\title{
ENTERING ROCINHA: A GIS APPROACH FOR THE IMPROVEMENT OF SOLID WASTE MANAGEMENT IN A SLUM IN RIO DE JANEIRO (BRAZIL)
}

\author{
Francesca Villa ${ }^{1,2, *}$, Andrea Arcidiacono ${ }^{3}$, Francesco Causone ${ }^{4}$, Gabriele Masera 5 , \\ Massimo Tadi ${ }^{5}$ and Mario Grosso ${ }^{1}$ \\ ${ }^{1}$ Department of Civil and Environmental Engeneering (DICA), Politecnico di Milano, via Golgi 39, 20133 Milan, Italy \\ ${ }^{2}$ Department of Civil, Environmental, Architectural Engineering and Mathematics, University of Brescia, via Branze 43, 25123 Brescia, \\ Italy \\ ${ }^{3}$ Department of Architecture and Urban Studies (DAStU), Politecnico di Milano, via Bonardi 3, 20133 Milan, Italy \\ ${ }^{4}$ Department of Energy, Politecnico di Milano, via Lambruschini 4a, 20156 Milan, Italy \\ ${ }^{5}$ Department of Architecture, Built Environment and Construction Engineering (DABC), Politecnico di Milano, via G. Ponzio 31, 20133 \\ Milan, Italy
}
Article Info:
Received:
14 April 2019
Revised:
8 January 2020
Accepted:
8 January 2020
Available online:
10 February 2020
Keywords:
Low-income countries
Informal sector
Solid waste management
Solid waste collection
Urban resilience
Informal settlements

\begin{abstract}
Solid waste management (SWM) is recognized worldwide as an important issue to be addressed with the aim of enhancing liveability. The Rocinha favela (slum) depicts a synthesis of the challenges to be faced in this field: high population density, lack of space and narrow streets, residents struggling with low incomes. In Rocinha, service coverage is lacking and inadequate in numerous sectors, including SWM. The present study investigates the reasons underlying this inadequacy. As an initial step, waste streams were analysed and the SWM system and its criticalities delineated. All accessible information was used, with Geographical Information Systems (GIS) playing an important role in data processing. In the final discussion, a small-scale and decentralized waste management network to be implemented in collaboration with the centralized collection system is suggested. This study was conducted as part of the Polimipararocinha project focussed on the overall urban re-qualification of Rocinha.
\end{abstract}

\section{INTRODUCTION}

Waste management in low-income countries is frequently called upon to deal with a series of challenges, as described by UN-HABITAT (2010a). From an economic point of view, the costs of waste management may account for up to $20-40 \%$ of the total costs sustained by municipalities, with coverage of these costs through fees proving difficult, particularly in poor areas. Inequalities in service provision may ensue as a consequence both of the above and discrimination.

Although Brazil is not formally considered a low-income country, but rather as a major emerging national economy (together with Russia, India, China and South Africa, they are referred to as the "BRICS" countries), inequality affects the distribution of wealth, with favelas representing one of the most evident signs. At the same time, this huge country has a vast experience in inclusion of the informal sector, particularly in the field of waste management (the case of waste-pickers or "catadores do lixo", organized in cooperatives) (Dias, 2011).
The settlement studied in this paper, Rocinha, recognised as a neighbourhood of Rio de Janeiro (RJ), is served with a series of public services (health, education, waste management, etc.) (EMOP, 2012). Urban plans and public policies for Rocinha have been developed, although they have either not always been adopted, or only partially and inefficiently adopted (Silva, 2015), and service coverage appears as lacking and inadequate. Moreover, Rocinha is characterized by numerous social conflicts, including "criminalization of poverty", presence of narco-traffickers, and generalized scarce trust in the institutions (Ceppi, 2017). Institutional lack of coordination may represent an obstacle to implementation of interventions (Rekow, 2016), potentially to an even greater degree than poor regulation. In this situation, a distinction should be made between sanitation (infrastructural and managerial choices) and hygiene (behavioural change and good practices) rather than placing the burden of an improper waste management on individual stakeholders.

The study was conducted as part of the Polimipararocin- 
ha project. A team made up of researchers and technicians with expertise in different areas (urban studies, architecture, energy efficiency, waste management, ecosystem service analysis, water management), worked together using the Integrated Modification Methodology (IMM) to define a comprehensive framework of interventions within Rocinha, aimed at transforming the favela into a more sustainable environment, whilst pursuing an improved quality of life for its inhabitants. To this regard, waste management is deemed fundamental in view of its acknowledged impacts on public health and the environment (Wilson et al., 2015).

\section{CONTEXT}

Rocinha is a neighbourhood of Rio de Janeiro, located in the southern part of the municipality (Figure 1). Rocinha is a favela or "comunidade" and was considered an informal settlement (slum) until 1993, when it was officially recognized by the Municipality of Rio de Janeiro. In 2012, a police pacification unit (UPP - Unidades de Polícia Pacificadora) was established as a strategy to maintain control of the territory against drug trafficking. Currently, several public services are located within Rocinha, including health centres (Centro de Saúde) and the national water and sanitation company (CEDAE - Companhia Estadual de Águas e Esgotos).

Located between two of the richest neighbourhoods of Rio de Janeiro, Rocinha is one of the poorest, with a Human Development Index (HDI) of 0.735 (IPP, 2017) and an economy mostly based on the informal sector (EMOP, 2010b).
It has a high population density, which is difficult to evaluate due to a series of varying estimates. Considering an area of 144 ha, the density for the year 2010 was approx. $500 \mathrm{inh} . /$ ha (IPP, 2017). The area rises between two granitic mountains with a morphology characterized by steep slopes, narrow alleys and lack of space.

These characteristics pose serious challenges to the establishment of an effective solid waste management (SWM) system. The location of containers is difficult throughout all areas, with only a few streets accessible to vehicles. The capacity of containers is apparently not sufficient to collect all the waste conferred, and the frequency of collection is inadequate. On moving away from the main road, waste is left on sidewalks and empty terrains or thrown inside drains and sewers. A concerted collection effort is therefore required for citizens living in poorly connected areas where waste dumping may derive from a traditional culture (Carvalho, 2016).

The consequences of improper waste management are well-known: water contamination; sanitation problems due to foraging of disease vectors such as rodents and insects; flooding caused by obstruction of drainage networks; collapse of waste masses onto surrounding buildings. All these issues, at times enhanced by the urban characteristics of the area, are present in Rocinha (EMOP, 2012).

\subsection{Functioning of the SWM system}

A description of the SWM system for the whole Municipality of Rio de Janeiro should first be provided to set the scene and clarify the current situation (PMGIRS, 2016;

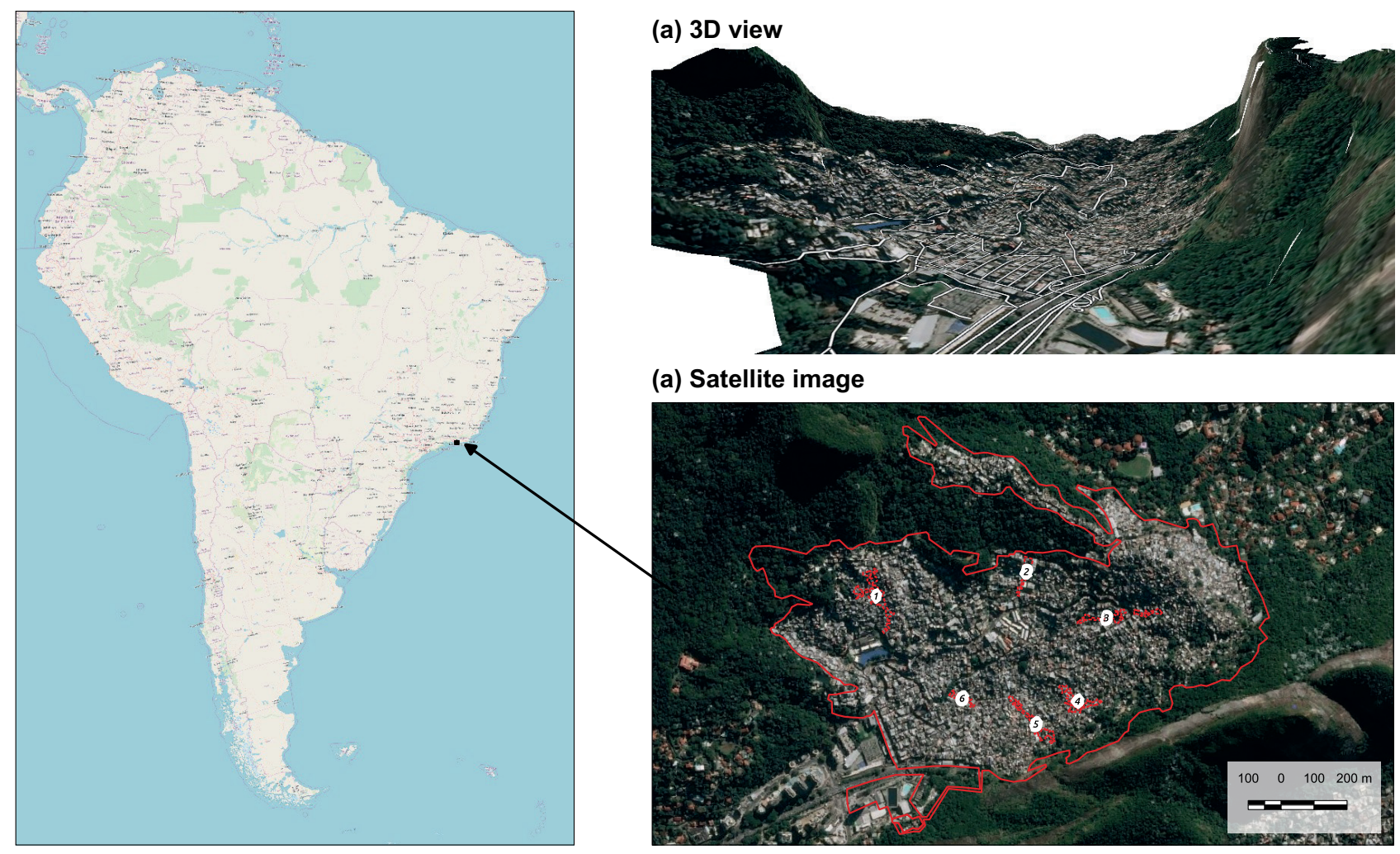

Contains map data: @ OpenStreetMap contributors (ODbL, www.openstreetmap.org); @ 2019 Microsoft (www.bing.com/maps)

FIGURE 1: Geographic location and context for Rocinha. 
EMOP, 2012; UFRJ, 2015). Both the Authorities responsible for the environment, sanitation and waste management and the respective legal frameworks are organised across three different administrative levels (federal, state, municipal) (EMOP, 2012). At a municipal level, the main focus is on legislation regulating Integrated Solid Waste Management. Other laws relate to separate collection, the downstream market for waste (with measures on the mandatory use of recycled waste in the works of the municipal public administration), and the informal sector. Laws related to other issues (sustainable development and climate change, water and sanitation, urban planning) should also be considered. Finally, several plans capable of impinging on waste management are present at a national and local level (e.g. Plano de Desenvolvimento Sustentável; Programa Alternativo de Coleta Seletiva; Lixo zero) (PMGIRS, 2016).

In 2011, a new logistic waste management system was developed for Rio de Janeiro, taking into account three steps (collection, temporary storage and final disposal). Comlurb is the public company responsible for waste collections, which are subsequently transferred to Waste Transfer Stations (Estações de Transferência de Resíduos - ETRs). ETRs receive MSW from Rio de Janeiro and other cities. Out of seven ETRs, the ETR Caju is dedicated to receiving waste from the AP2 area, which includes Rocinha. Waste from the ETRs is then forwarded to the Waste Treatment Centre CTR-Rio at Seropédica, opened in 2011.

In 2014, Comlurb managed the collection of $8370 \mathrm{t} / \mathrm{d}$ of waste on average for the city of Rio de Janeiro, corresponding to $91 \%$ of an overall $9227 \mathrm{t} / \mathrm{d}$ received by Transfer Stations (ETRs). This waste stream was sent to CTRRio Seropédica (93.2\%); separate collection accounted for 0.5\% (PMGIRS, 2016).

The collection system in Rocinha has been described by several authors (Toledo, 2009; Azevedo, 2010; EMOP, 2012). Comlurb operates inside the favela and is responsible for waste collection, cleaning of public areas and maintenance of green spaces and street furniture. Street cleaning and waste collection may also be performed by the "gari comunitario", a street-sweeper identified by residents' associations, when streets and alleys are too narrow to allow the passage of vehicles. Tractors and small compactor trucks are used within Rocinha, together with several types of containers (compactors of about $15 \mathrm{~m}^{3}$, skips of 1-2 $\mathrm{m}^{3}$, dumpsters of $1.5 \mathrm{~m}^{3}$ ) and concrete slabs for street collection. Approximately one hundred people are purported to be involved in waste collection within Rocinha.

\section{POLIMIPARAROCINHA PROJECT}

The project builds on the collaboration with a NonGovernmental Organization (NGO), "Il sorriso dei miei bimbi", located in Rocinha. The NGO invited the researcher to implement a scientific approach in an attempt to identify strategies aimed at improving the overall liveability of the favela.

The theoretical background of the project is underpinned by the Integrated Modification Methodology (IMM), aligned with the UN Sustainable Development Goals (SDGs) 2030. One of the 17 goals identified within this framework,
SDG 11, relates specifically to cities and human settlements and how to render these inclusive, resilient and sustainable. According to the IMM approach, cities are regarded as Complex Adaptive Systems (CAS), with the main focus being on simulating their operative mechanisms, involving both the internal subsystems and external systems that the cities are part of. The result is a methodological interpretation of the SDG Number 11 (Sustainable cities and communities), suggesting locally-based actions.

\subsection{The Integrated Modification Methodology (IMM)}

IMM methodology is based on a multi-stage process composed of five integrated phases, respectively: Investigation, Formulation, Modification, Retrofitting and Optimization. IMM intends to assist city-planners and decisionmakers by providing them with a fully-integrated design process to transform an existing urban context into a more sustainable one. Starting out from SDG 11, IMM systematically provides a holistic correlation with all other SDGs (Tadi and Vahabzadeh Manesh, 2014).

IMM attempts to modify the behaviour of the entire complex system by means of local intervention scenarios. Based on morphological and functional arrangements, IMM devises a local system mapping used both to investigate the base and predict future scenarios with the aim of improving an existing system. This process allows the identification of areas in which the potential of the context is unexpressed and where major resources exist. Following application of the IMM, Rocinha was considered a specific urban CAS and analysed to assess performance. In particular, the investigation phase highlighted how Rocinha is affected by a lack of open spaces and an existing street network unsuited to providing adequate links and ready access.

Accordingly, the transformation concept is driven by an aim to provide additional open spaces and boost the integrity of street networks by relocating a small number of low-rise buildings where possible and beneficial. The research project comprised an objective evaluation of the morphological organization and related environmental performances and qualities, focusing on different sectors of intervention.

\subsection{Waste and other sectors of intervention}

As previously explained, one of the pillars of the methodology lies in assessing the link between the different sectors of intervention and their relationship with urban morphology, pursuing a multidisciplinary and integrated approach. In addition to waste management, the main focus of the present research, other related sectors include energy, ecosystem services, wastewater, mobility and food. These will be described briefly in the following paragraphs.

\subsubsection{Energy}

The energy project aims to fulfil the basic electrical needs of the low-income households of the favela by exploiting solar energy through photovoltaic panels installed on the rooftop of buildings where incident solar radiation is abundant. By doing so, solar energy exploitation will also be able to reduce electricity theft and increase grid relia- 
bility inside the favela. Simple access to electricity should be considered while exploring the waste management system, with particular focus on household-level solutions. Furthermore, the exploitation of waste as a source of energy may be evaluated.

\subsubsection{Ecosystem Services}

An Ecosystem Services (ES) based approach was applied to estimate environmental conditions in view of the fact that urban liveability is influenced by natural resources (e.g. soil, air and water). Compromised and environmentally-degraded areas, more subject to potential disaster events such as landslides or flooding, were identified. The ES-based approach is pivotal in setting nature-based solutions (NBS) to contrast risks and improve both urban ES and local quality of life. NBS use natural processes and ES for functional purposes, addressing ecological, social and economic challenges. In this case, NBS mitigate flood, drought, erosion and landslide. Improper waste management influences flooding, largely caused by the clogging of drains.

\subsubsection{Mobility}

The current mobility system of Rocinha presents a series of critical issues. Many recent studies carried out to investigate mobility in the favelas highlighted the need to improve the general accessibility of these communities through interventions focused on supporting the non-motorized sector, in particular by implementing bicycle-based systems. The "Rio Conecta" plan for mobility also enhances this aspect. The lack of an integrated mobility system capable of supporting the existing subway station means that the underground is able to cover only limited areas alongside the main street of Rocinha. Following analysis of both the road network and mobility index value, an affordable and integrated electric bike-sharing system has been identified as a priority. The bikes will be charged using locally produced energy, and the whole system linked to an Urban Management System (UMS), which will collect mobility data for further transportation strategies. Limited accessibility is a major obstacle for waste collection, strongly influencing waste management. The proposed solution for Rocinha will consequently take into account conclusions arising from this analysis.

\subsubsection{Water and wastewater}

The collection of wastewater and rainwaters is fundamental to protect public health and provide for an appropriate management of the territory. A "pilot" area has been identified on which to implement the proposed procedures. Sewer systems were sized based on a water supply of 150 L/day per capita, envisaging collection of $80 \%$ of the supplied water in the sewage. Resulting overall discharges are very low, which could lead to settling and therefore septic problems. However, the diameter of network ducts was set at $150 \mathrm{~mm}$ to avoid problems of occlusion. The possibility of conveying a small percentage of rainwater to "clean" the pipes when necessary was considered. The designed pipelines are easy to lay and inspect, and, during construction, must be protected against possible mechanical and climate-induced damage. Water should undergo treatment prior to release into the environment.

Although not strictly related to hydraulic aspects, the need for direct community involvement should be highlighted - both to guarantee a correct use of the network (for example, no solid waste should be discharged into the pipes) and provide for improved land management. Community involvement will allow contribute towards raising awareness and fostering interest in the work; a skills workshop will be set up to train the users in correct construction and sewage network management techniques, which would help to generate an economic activity, albeit small.

\subsubsection{Food}

Food quality and nutritional awareness represents a crucial issue for the majority of the Rocinha children and their parents, who have scarce access to fresh food and receive no information on how to eat healthily. Rocinha is characterized by a high population density and almost total absence of voids, with the steepness of the territory rendering any kind of traditional cultivation impossible. The project therefore envisaged the implementation of a series of innovative sustainable urban agriculture strategies, e.g. green roofs, vertical farming and aquaponics. Besides providing fresh fruit and vegetables, this intervention aims to boost the local economies. Food concerns are also closely linked to water issues (gardens increase drainage of impermeable surfaces that otherwise generate critical runoff) and to the waste sector that promotes the local use of compost derived from organic waste.

\section{MATERIALS AND METHODS}

The purpose of the study was to suggest a series of potential improvements to be applied to the SWM system in Rocinha. The first step was to create a comprehensive picture of the situation, identifying existing waste flows and estimating the amount and composition of the same. Consequently, efforts were made to collect and analyse all available data to define a baseline.

Subsequently, a geographical analysis was performed in view of the fact that organization of a solid waste management system is interlinked to the topology of the target area, including the distribution of buildings and street network. Data related to waste generation were used in this stage to clarify the distribution of solid waste within Rocinha.

Finally, this framework was used to add consistency to a new proposal for waste management, scaled on the six pilot zones identified by the project.

Details on data sources and analytical methods are provided below.

\subsection{Data analysis}

All available data from public sources was collected to evaluate the amount of waste generated in Rocinha and its composition. Existing data was largely based on information provided by Comlurb, although other sources were also consulted. When possible, complete data series 
were used for analysis (IPP, 2017; IBGE, 2017; SNIS, 2017) and aggregated data were used to correct or validate the estimate (PMGIRS, 2016; EMOP, 2012; UFRJ, 2015). The analysis was performed using the open-source software RStat and related packages (R Core Team, 2015; Wickham, 2007; 2009; 2011).

Data on the composition of waste was only available for Household waste. For the whole Municipality of Rio de Janeiro, data was first collected in 1981 (Lima and Sorliuga, 2000; Comlurb, 2012), while data for Rocinha were only available for one single year (Comlurb, 2012). Numerical data for both Rio de Janeiro and Rocinha is listed in Table 1. Data display a coherent picture, which was taken as the basis for the assessment.

Finally, the number of inhabitants of Rocinha was estimated. Evaluating the population of an informal settlement is not an easy task due to the lack of reliable information. Official data range from approx.70,000 (IBGE, 2010) to 100,000 (EMOP, 2010) inhabitants. The electricity provider Light S.A. estimates 165,000 inhabitants, while citizens' associations suggest a range between 180,000 and 220,000 people. Calculations presented in this paper assume 211,000 inhabitants, based on the Polimipararocinha project best guess, although further statistical and demographic analysis is required.

\subsection{Geographical analysis}

The analysis was performed using the open-source software QGIS and related plugins (QGIS, 2017).

The base map for the analysis, a shapefile containing every single building with an estimate of the number of floors, was prepared and is being kept updated by the

TABLE 1: Characterization of Households waste in Rio de Janeiro (RJ) and Rocinha for the year 2012, weight percentage (GPA, 2012).

\begin{tabular}{|c|c|c|}
\hline Fraction & Rio de Janeiro (\%) & Rocinha (\%) \\
\hline Paper / Cardboard & 15.99 & 11 \\
\hline Plastic & 19.14 & 21.82 \\
\hline Glass & 3.28 & 0.5 \\
\hline Organic matter & 53.28 & 60.67 \\
\hline Metal & 1.57 & 1.69 \\
\hline Inert waste & 1.81 & 1.11 \\
\hline Leaves & 1.35 & 0.52 \\
\hline Wood & 0.34 & 0 \\
\hline Rubber \& tyres & 0.22 & 0.44 \\
\hline Tissues & 1.76 & 1.11 \\
\hline Leather & 0.21 & 0 \\
\hline Bones & 0.01 & 0 \\
\hline Coconut & 0.82 & 0 \\
\hline Paraffin & 0.05 & 0 \\
\hline E-waste & 0.2 & 1.04 \\
\hline Total & 100 & 100 \\
\hline Specific weight $\left(\mathrm{kg} / \mathrm{m}^{3}\right)$ & 133.02 & 111.17 \\
\hline Moisture content (\%) & 36.57 & 39.46 \\
\hline
\end{tabular}

Universidade Federal do Rio de Janeiro (UFRJ). Other geographical information, i.e. data relating to administrative boundaries and Census areas, are available online on the website of the Municipality of Rio de Janeiro (IPP, 2017).

The first step was to define the number of inhabitants per building. As a first estimate, all buildings were assumed to be residential, and the total floor area calculated by multiplying the number of floors of each building by its ground floor area. The population of Rocinha was divided by the total floor area, yielding a value of $0.17 \mathrm{inh} . / \mathrm{m}^{2}$, which was used to assign a defined number of inhabitants to each building. The number of inhabitants multiplied by the daily per capita generation of waste provided a map of the distribution of waste produced in Rocinha, useful for a general overview but also in calibrating intervention on the pilot zones.

A second step was carried out to ascertain the situation of collection points within the favela. Maps describing the location of waste containers in Rocinha were found in previous studies (Azevedo, 2010; EMOP, 2012) and partially updated by means of a manual inspection using GoogleStreetView. To estimate the amount of waste reaching each collection point, Voronoi polygons were used. The Voronoi region for each point represents the set of points in the plane for which that point is the closest (Fortune, 1987); consequently, the sum of the amount of waste calculated for each building included in the Voronoi region will represent the amount of waste reaching the related collection points.

\section{RESULTS}

\subsection{Solid waste flows for Rio de Janeiro and Rocinha}

All available quantitative information relating to waste in Rocinha was gathered. A database was prepared, considering the following entries: year; numeric value; unit of measure; location (boundaries of the area); phase (production, collection or disposal); source (whether the waste originated from households, street sweeping, etc.); who performed the collection; final destination of the waste; reference for data; material fraction (food waste, metals, plastic, etc.); type of data (whether estimated, measured, or derived from a survey). Information relating to each parameter was not always available.

The database represented the starting point for analysis; several waste streams (depending on the source of the waste), collected by Comlurb or by private enterprises and forwarded to a series of final destinations, were identified. In the collection phase, the total waste quantities may be divided into different streams:

Public waste, from street cleaning and sweeping;

PublicGreen, green public waste from pruning and cutting;

- FreeRemoval, bulky waste removed for free by a specific service provided by Comlurb;

Household waste, also referred to as "domestic" waste; RCC, Construction and Demolition waste;

RSS, Healthcare waste;

Separate collection. 
The role of waste pickers ("catadores") was not considered in this calculation as no available data accounted for their involvement.

Information was available only for Rio de Janeiro, but not for Rocinha. Consequently, the data available for Rocinha was corrected based on the results obtained from analysis of solid waste flows in the main city, as described below.

The only data available for Rocinha related to the collection of Public and Household waste by Comlurb . Moreover, public waste (Public2) was an aggregated data comprehensive of Public, Public Green and FreeRemoval waste, as previously described.

As a first step, both Public2 and Household waste were increased to take into account the contribution of the Private sector, accounting for $11 \%$ of the total amount of collected Public, PublicGreen and FreeRemoval waste, and $16 \%$ of the total amount of collected Household waste in Rio de Janeiro.

Public2 waste was then sub-divided into Public, PublicGreen and FreeRemoval waste, and percentages related to other waste streams (RCC, RSS, Separate collection) were estimated. These results, representing the collection phase, are described in Figure 2.

Data presented in Figure 2 represent solely the percentage of waste collected by public or private enterprises; however, the percentage of waste which is not appropriately collected should also be evaluated in order to estimate overall waste generation. In Rio de Janeiro, approximately $59 \%$ of Household waste is estimated as being appropriately collected, while the remaining $41 \%$ is not collected and is improperly disposed of (burned, buried, dumped, etc.) (UFRJ, 2015). The amount of collected waste in Rocinha was consequently increased by calculating the amount of improperly collected Household waste (18,870 t per year) to estimate the amount of total produced waste $(60,411 \mathrm{t}$ per year in 2014). The final daily solid waste production of approx. $166 \mathrm{t}$ is in line with the estimate of $152 \mathrm{t} / \mathrm{d}$ by EMOP (2012).

Considering a population of 211,000 inhabitants, the daily per capita generation of total solid waste is estimated at $0.78 \mathrm{~kg} / \mathrm{d} / \mathrm{inh}$., while the daily per capita production of Household waste is estimated at $0.59 \mathrm{~kg} / \mathrm{d} / \mathrm{inh}$.

\subsection{Distribution of solid waste within Rocinha}

The daily per capita production of Household waste was used to calculate the daily production of Household waste for each building (Figure 3, (a) Base map). Voronoi regions were subsequently calculated for each formal ("Collection point") or informal ("Dumping point") collection point. Figure 3 (b) Elaboration, illustrates Collection points and Dumping points using different sizes depending on the amount of waste conferred to each point, ranging from less than 100 to more than $7000 \mathrm{~kg}$ per each day.

When applied to the real world, the choice of Voronoi regions represents an approximation which fails to take into account the presence or absence of streets or alleys, or the differences in altitude that characterise Rocinha. Nonetheless, the choice made was based on the lack of a detailed map of streets and alleys.

The map presented in Figure 3 represents an initial tool for use in the identification of critical points, yielding a first estimate of the equipment (such as containers) needed. Moreover, the amount of waste disposed of at each collection point may be used as a proxy of the impact of the intervention described in the next paragraph.

\subsection{A new proposal}

The proposal intended to improve the solid waste management system in Rocinha was based largely on a detailed analysis of the current state-of-the-art. Previous studies, which had identified three major stakeholders (companies,

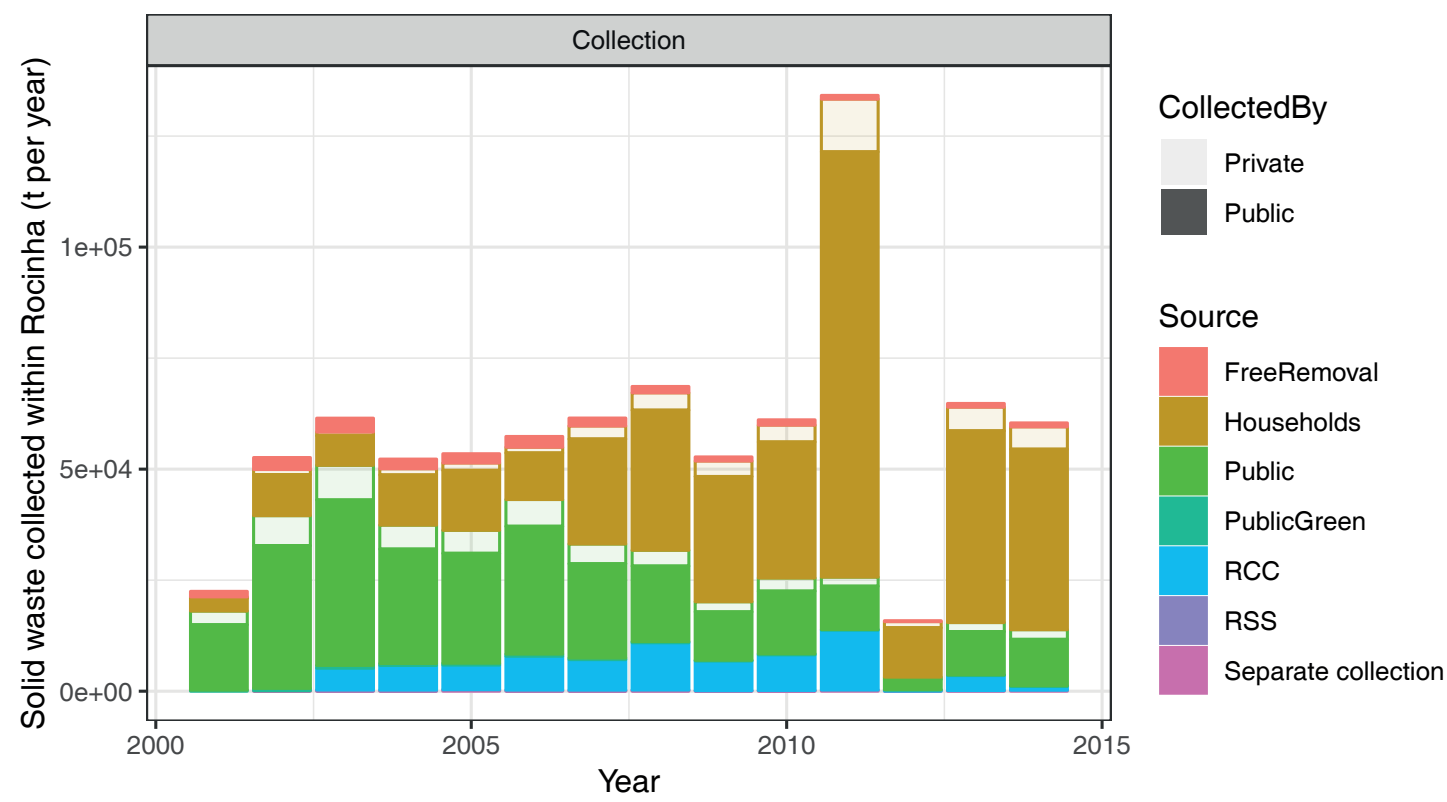

FIGURE 2: Rocinha: solid waste streams in the collection phase from 2001 to 2014. 
local communities, public authorities), and detailed actions or solutions (Azevedo, 2010), such as underground containers, to be implemented with an aim to tackling the problem of space (EMOP, 2012), were also considered. It should however be underlined that none of these proposals has yet been implemented due to conflicts between the State and the municipal management (Silva, 2014).

The current situation may be summarized as follows: waste collection is not guaranteed throughout the favela due to its morphological characteristics, logistic concerns and lack of resources. Together with a scarce environmental awareness, this leads to improper disposal of waste, exacerbating other issues which may over time result in a situation of emergency (floods or disease outbreaks). The need to deal with emergencies drains the already scarce resources from the overall system. In an attempt to overcome this vicious circle, a collection system operating parallel to the existing system managed by Comlurb has

(a) Base map

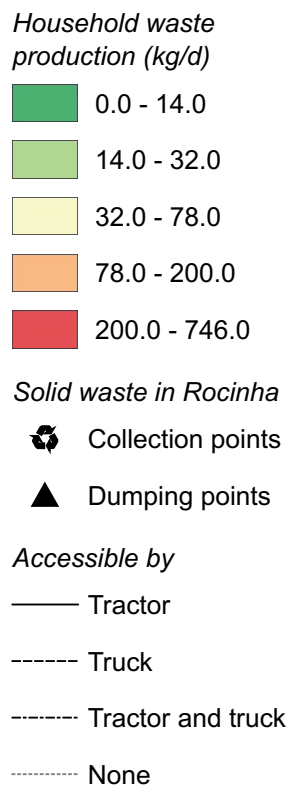

(b) Elaboration

Household waste production $(\mathrm{kg} / \mathrm{d})$

\begin{tabular}{|l|l|}
\hline & $37-1452$ \\
\hline$\quad$ & $1452-2866$ \\
\hline$\quad$ & $2866-4281$ \\
$\square \quad$ & $4281-5695$ \\
$\square \quad$ & $5695-7110$
\end{tabular}

Daily amount of Household waste $(t / d)$ reaching:

Collection points

Dumping points
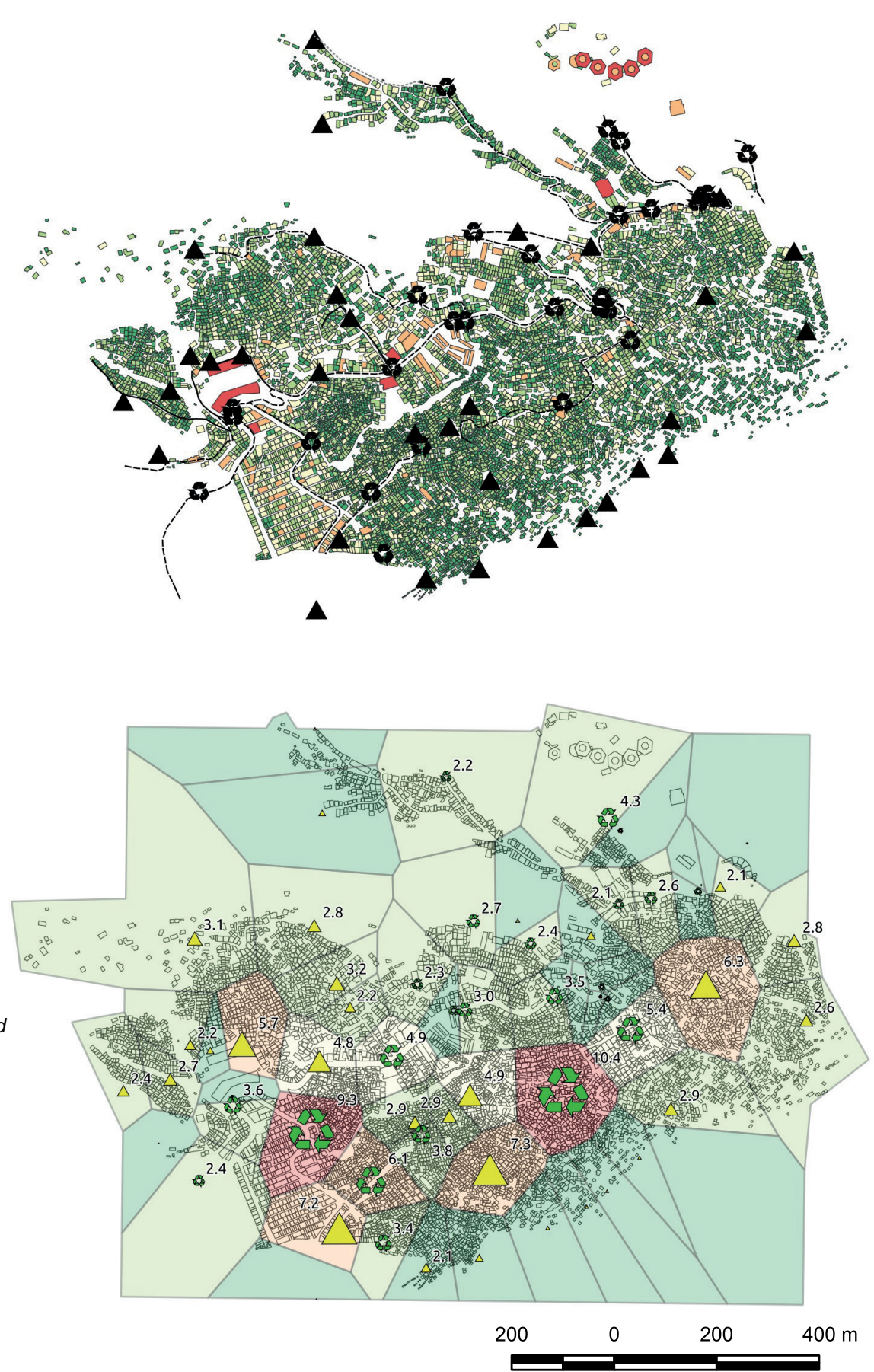

FIGURE 3: Household waste production in Rocinha: (a) Base map - daily production for each building, location of Collection and Dumping points, collection routes; (b) Elaboration - Household waste production per area ( $\mathrm{kg} / \mathrm{d}$ ) and daily amount conferred at each point of disposal $(\mathrm{t} / \mathrm{d})$. 
been devised to divert valuable materials from the general waste collection. This collection system will be organized in small-scale nodes, each representing the focal point for the whole collection system in a specific area. In each node, a group of workers operating either independently or in cooperatives, will assume responsibility for waste management. All nodes will be connected in a network. Separate collection of Household waste will be implemented, targeting both the organic fraction and recyclables, with sale of recyclables representing a source of income for people involved in the system.

The reasons for this proposal can be summarized as follows.

First, the choice to proceed with small scale interventions requires little investment. This will consequently allow for a series of different strategies: the establishment of nodes may be promoted and coordinated by institutions, although may even arise as a grass-root initiative moving from local communities and stakeholders with a high environmental concern (e.g. community-based organizations) or an economic interest (e.g. waste pickers).

An important example is provided by the cooperative Rocinha Recicla, established in 2016 in the context of the project "De Olho No Lixo" (promoted by the State of Rio de Janeiro) (INEA, 2016). Rocinha Recicla employed up to 30 workers, all resident in Rocinha, and is currently focused on the cleaning of roads and water channels, together with a series of other awareness-raising activities: Ecomoda, a dressmaking laboratory using recovered waste fabrics, and FunkVerde, a workshop for the production of musical instruments using discarded materials. Until November 2018, Rocinha Recicla managed a warehouse in which recovered materials (plastic, metals, paper and cardboard) collected by its workers or by autonomous waste pickers were prepared for sale, and soap was produced from exhaust kitchen oil. The warehouse was subsequently demolished by the Municipality of Rio de Janeiro without notice (INEA, 2018), and the cooperative is currently awaiting the assignment of a new location, as promised by the authorities.

When activities resume, Rocinha Recicla, together with its laboratories Ecomoda and FunkVerde, should be considered an important node of the entire network. Waste pickers, many of whom already collaborate with the cooperative, should also be involved in this system. Brazil has a long tradition of self-organization of this informal economy sector, with previous experiences maintaining how waste pickers benefit from a higher level of organization: the existence of a network will allow scale economies to be implemented, including shared use of equipment (such as presses, shredders, etc.) and improved access to the secondary raw material market.

Secondly, the promotion of separate collection at a household level is fundamental to obtain high quality secondary raw materials and provide a safer working environment for collection workers. Separate collection will target recyclable waste (plastic, metals and paper/cardboard) with a high (potential) economic value. Moreover, since recyclables from Rocinha are not currently forwarded to any sorting plant, this diversion will produce no negative effect on the cooperatives involved in waste separation in other nodes of the waste collection system of Rio de Janeiro.

The abundant organic fraction present in Rocinha will also be targeted. An important goal of the project is to reduce the amount of waste improperly disposed of, with the aim of improving public health and safety. This fraction has been estimated as corresponding to approx. $41 \%$ of the Household waste generated, and this value accordingly adopted as the target amount to be diverted by means of separate collection. Analysis has revealed how this value is achievable solely if both recyclables and the organic waste fraction are targeted. Threshold values for the efficiency of separate collection to be achieved over the medium term are in the range of approx. $45 \%$ for the organic fraction and $73 \%$ for recyclables (plastic, metals and paper/cardboard).

Finally, the strategy is focused especially on collection, as only a small portion of the waste will be treated inside Rocinha. This amount will vary depending on land availability, considering that the on-site recycling of waste requires space for storage and treatment, which represents a considerable constraint for Rocinha. Waste not managed within the proposed intervention will be forwarded to the official collection point managed by Comlurb and will enter into the system described in Paragraph 2.1.

\subsubsection{Organization of the new system}

In the context of the general framework of this strategy, an organizational proposal has been elaborated. For each node, a series of actions relating to the individual stages will be evaluated: separate collection, primary storage, local treatment and awareness. These actions may be described as follows:

- Separate collection is based on the distribution of street containers for conferment of the organic fraction and recyclables. However, innovative solutions aimed at addressing the lack of space within Rocinha should be identified. Alternative solutions (door-to-door collection, location in schools or other facilities) may be explored.

- "Eco-Centres" are designed for the primary storage of recyclables. The storage period is linked to space availability (less space, shorter period) and also on the size of the vehicles accessing the Eco-Centre (smaller vehicles, a shorter period of storage OR a higher number of trips).

- A multi-purpose hexagonal structure, known as the "Ecoponto Kiosk", will serve as: information point to explain the functioning of the SWM system and raise awareness; distribution point for items to enhance separate collection, recycling and re-use of materials (paper bags for organic collection, "take-back" glass bottles, locally produced compost) and Personal Protective Equipment (PPE) for waste workers; collection of paper, metals and plastic.

The feasibility of local treatment of the organic fraction will be assessed for both composting and anaerobic digestion, depending on the local situation (e.g. land availability, distance from buildings, demand for compost in the 
surrounding areas...). Composting may indeed be divided into sub-modules and managed on a community basis, with little labour cost. The compost can be used in synergy with other actions proposed within the project: land restoration for the mitigation of hydraulic risk (see 3.1 Ecosystem services) or vertical garden for the local production of food (see 3.5 Food). The compost may also be used in the maintenance of green areas, and, if high-quality levels are achieved, eventually sold on a local market. The anaerobic digester will be designed according to a local project implemented in Rio de Janeiro (Mattos and Farias, 2011). Both safety issues, such as the need for a buffer zone around the digester, and environmental issues, will be taken into consideration: for example, the potential for local use of the produced biogas should be evaluated to avoid any leakage (methane poses a high risk of fire and explosion).

\subsubsection{Analysing the impact of the intervention}

The study presented in this paper aims to provide technical support for the establishment of a node. Indeed, following the initial identification of an area, the study will allow the amount of waste produced within the specific area, together with the quantities of organic and valuable fractions such as paper, plastic and metals, to be calculated. Subsequently, the space required for street collection, storage and local treatments can be assessed and appropriate locations identified.

An analysis performed on the six zones identified within the Polimipararocinha project is presented as an example of the procedure.
Design choices are summarized hereafter:

- Separate collection. The size of the containers was calculated considering typical specific bulk weights for each fraction (organic: $0.3 \mathrm{t} / \mathrm{m}^{3}$; paper: $0.13 \mathrm{t} / \mathrm{m}^{3}$; plastic: $0.072 \mathrm{t} / \mathrm{m}^{3}$; metals: $0.12 \mathrm{t} / \mathrm{m}^{3}$ ) and a maximum weight of $80 \mathrm{~kg}$ for the full container. Collection is performed daily.

- "Eco-centres" feature a maximum height of $2 \mathrm{~m}$. Maximum storage period was set at 7 days as a first choice.

- The "Ecoponto Kiosk" has a side of 2.5 m, a total surface area of approx. $16 \mathrm{~m}^{2}$, and can accommodate a volume of up to $1.83 \mathrm{~m}^{3}$ of plastic, $1.1 \mathrm{~m}^{3}$ of paper and $0.3 \mathrm{~m}^{3}$ of metal. The "Ecoponto Kiosk" will be located in areas currently devoid of structures.

- Composting slabs will have a maximum height of 1.5 $\mathrm{m}$, and a width of $2 \mathrm{~m}$ at the bottom and $1.5 \mathrm{~m}$ at the top; the depth of the smaller module will reach approx. $2 \mathrm{~m}$; a reduction of circa $30 \%$ of the volume is hypothesised. The anaerobic digester is circular shaped with 2 $\mathrm{m}$ radius and requires a circular buffer zone with $10 \mathrm{~m}$ radius. Retention time is assumed to be 30 days.

The final results are compiled in Table 2. For each zone, the area required for the implementation of each strategy is presented, together with the impact on the available empty spaces existing in each specific area. The number of containers required for each zone has also been calculated.

The impact produced on empty spaces is minor, with the exception of the anaerobic digester, which requires a safety zone and can only be realized in Zone 2 . The inter-

TABLE 2: Design of the new system for waste management in the six pilot zones of the project.

\begin{tabular}{|c|c|c|c|c|c|c|c|}
\hline & Zone 1 & Zone 2 & Zone 3 & Zone 4 & Zone 5 & Zone 6 & Total \\
\hline Number of inhabitants & 4058 & 4166 & 4774 & 4404 & 4227 & 2234 & 23863 \\
\hline $\begin{array}{l}\text { Amount of diverted waste } \\
\text { Weight }(t / d) \text {, of which }\end{array}$ & 1.26 & 1.30 & 1.49 & 1.37 & 1.32 & 0.70 & 7.44 \\
\hline - Organic fraction & 0.66 & 0.67 & 0.77 & 0.71 & 0.68 & 0.36 & 3.85 \\
\hline - Plastic & 0.38 & 0.39 & 0.45 & 0.42 & 0.4 & 0.21 & 2.25 \\
\hline - Paper & 0.19 & 0.2 & 0.23 & 0.21 & 0.2 & 0.11 & 1.14 \\
\hline - Metal & 0.03 & 0.03 & 0.03 & 0.03 & 0.03 & 0.02 & 0.16 \\
\hline - Volume $\left(\mathrm{m}^{3} / \mathrm{d}\right)$ & 9.24 & 9.49 & 10.87 & 10.03 & 9.63 & 5.09 & 54.4 \\
\hline Total area required $\left(\mathrm{m}^{2}\right)$ : & 98 & 486 & 115 & 108 & 88 & 62 & \\
\hline Primary storage $\left(\mathrm{m}^{2}\right)$ & 4 & 7 & 7 & 7 & 7 & 3 & \\
\hline Ecoponto Kiosk (m²) & 16 & No & 16 & 16 & No & 16 & \\
\hline Secondary storage $\left(\mathrm{m}^{2}\right)$ & 25 & 26 & 30 & 28 & 26 & 14 & \\
\hline Composting $\left(\mathrm{m}^{2}\right)$ & 53 & - & 62 & 57 & 55 & 29 & \\
\hline Anaerobic digester $\left(\mathrm{m}^{2}\right)$ & - & 452 & - & - & - & - & \\
\hline Impact on empty spaces & $5 \%$ & $36 \%$ & $6 \%$ & $6 \%$ & $7 \%$ & $14 \%$ & \\
\hline \multicolumn{8}{|l|}{ Equipment required: } \\
\hline Metals - Bins $0.12 \mathrm{~m}^{3}$ & 0 & 2 & 1 & 0 & 2 & 0 & \\
\hline Paper - Bins $0.24 \mathrm{~m}^{3}$ & 2 & 6 & 4 & 4 & 6 & 0 & \\
\hline Organic - Bins $0.24 \mathrm{~m}^{3}$ & 10 & 12 & 12 & 12 & 12 & 6 & \\
\hline Plastic- Cages $2 \mathrm{~m}^{3}$ & 2 & 4 & 4 & 4 & 4 & 2 & \\
\hline
\end{tabular}


vention on six zones will affect approx. 24,000 inhabitants ( $11 \%$ of the population in Rocinha).

Zones are shown in Figure 4, together with collection or dumping points which will be affected by the implementation of the project. The reduction of Household waste disposed of at each point is shown as a percentage: it is noteworthy to observe the impact on dumping sites surrounding Zone 1 (20\% and 22\%) and Zone 5 (25\%), while percentages of approx. $50 \%$ are perceived in the vicinity of Zone 4 . An approximately $46 \%$ reduction in official collection points will result in an increased collection capacity.

\section{CONCLUSIONS AND PERSPECTIVES}

The analysis conducted, yielding a preliminary estimation of the distribution of solid waste generation within Rocinha, may prove valuable in the decision-making process for solid waste management.

The method proposed for use in evaluating impact of the intervention can be rapidly applied to different areas, facilitating a preliminary estimation in terms of equipment and spaces needed; this estimation may then be used in support of funding applications. The application of a method based on information gathered and analysed remotely may contribute towards reducing the typically timeexpensive planning stage, saving resources which can be consequently be assigned to field data collection and feasibility studies.

Should the proposed intervention be implemented, it is likely to produce a positive impact on the existing situation. A small investment would foster a general improvement of the SWM system. Moreover, in terms of space required, the solution would appear to be compatible with the high population density in Rocinha. Finally, this small-scale approach based on involvement of the informal sector is a good fit with the relative socio-cultural context.

Successful implementation of this proposal would however need to take into account a series of different aspects, as briefly listed below.

A comprehensive economic analysis would be needed, to understand whether the system would prove to be selfsustainable or may be contingent upon public investments.

The participating stakeholders (public authorities, the academy, civil society organizations and NGOs, companies, and waste pickers) should subsequently be identified; the involvement of these stakeholders if of the utmost importance, as a high level of community engagement is mandatory in achieving an effective waste management system. To this regard, the lively civil society of Rocinha would undoubtedly play a key role in the successful implementation of the system and raising of awareness.

The potential integration of the proposal with other institutional programs should also be evaluated, bearing in mind the numerous initiatives undertaken in the past. An agreement should be reached with Comlurb to diversify management of the collection, cover a larger number of areas, and to obtain institutional or economic support of other projects. Every effort should ultimately be taken to avoid conflicts that might negatively affect the successful outcome of the project.

\section{ACKNOWLEDGEMENTS}

The authors would like to thank: the Polisocial program of Politecnico di Milano, which funded the research; the NGO "Il sorriso dei miei bimbi" for precious insights from the heart of Rocinha; the team of the Federal University of Rio de Janeiro (UFRJ), and in particular Gabriella Rossi,

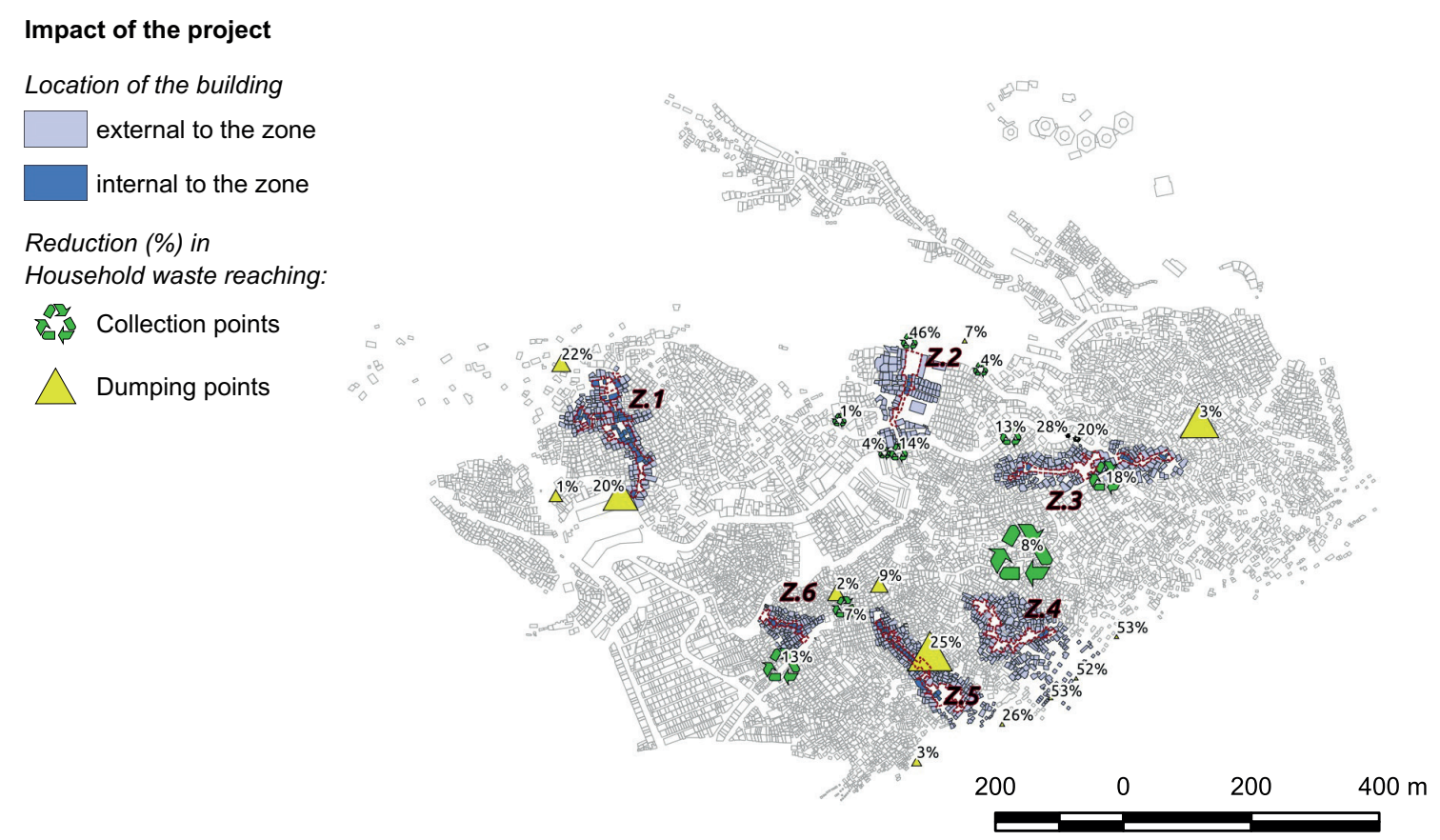

FIGURE 4: Impact of the implementation of the project on the pilot zones: reduction of Household waste reaching collection and dumping points $(\mathrm{t} / \mathrm{d})$. 
Gisele Silva Barbosa and Roberto Machado Correa; Marco Contardi and Pietro Ceppi from the Foundation Getulio Vargas (FGV); Maria Izabel de Carvalho for sharing her social-based perspective on waste management issues in Rocinha, her hometown; Professor Stefano Mambretti and Professor Gianfranco Becciu; Silvia Ronchi, Hadi Mohammad Zadeh and Anita Tatti, the operational team of Polimipararocinha project, for their efforts.

\section{REFERENCES}

Azevedo, B. D., Scavarda L.F. 2010. Análise e proposta de diretrizes para um sistema logístico de recolha e beneficiamento dos resíduos sólidos para áreas de favela em sintonia com os preceitos do GrSCM, Master Thesis in Industrial Engineering, Pontifícia Universidade Católica do Rio de Janeiro (PUC-RJ)

Azevedo B.D. and Cardoso C. ("Plano de Gerenciamento de Resíduos Sólidos da Rocinha")

Carvalho, M.I., Bastos, V.P., 2016. A favela da Rocinha e a destinação inadequada de lixo: entendendo os meandros da questão, Master Thesis in Social Service, (PUC-RJ)

Ceppi P., 2017. Bringing the State to the Favela - An Assessment of the State-Building Process through Slum Upgrading in the Favela of Rocinha, Master Thesis in Global Development, Faculty of Social Science, University of Copenhagen.

Dias, S. M., 2011. Integrating Informal Workers into Selective Waste Collection: The Case of Belo Horizonte, Brazil, Women in Informal Employment Global Organization (WIEGO), Policy Brief (Urban Policies), N.4

Comlurb, 2012. Determinação do Peso Específico de diversos tipos de resíduos sólidos, Gerência De Pesquisas Aplicadas, Companhia Municipal de Limpeza Urbana, Prefeitura do Rio de Janeiro

EMOP, 2012. Relatório de Diagnóstico Urbano, Ambiental e Social, Empresa Municipal Das Obras Publicas (EMOP), Estado do Rio do Janeiro

EMOP, 2010a. Complexo da Rocinha, Rio de Janeiro - Relatório Final Censo Domiciliar, EMOP

EMOP, 2010b. Complexo da Rocinha, Rio de Janeiro - Relatório Final Censo Empresarial, EMOP

Fortune, S.J., (1987). A Sweepline Algorithm for Voronoi Diagrams, Algorithmica 2, 153-174.

GRASS Development Team, 2017. Geographic Resources Analysis Support System (GRASS) Software, Version 7.2. Open Source Geospatial Foundation. Online at: http://grass.osgeo.org

INEA, 2018. Nota à Imprensa - Projeto de Olho no Lixo, Instituto Estadual do Ambiente, News, $16^{\text {th }}$ of November 2018, Online at: http:// www.inea.rj.gov.br/nota-a-imprensa-projeto-de-olho-no-lixo/

INEA, 2016. Secretário do Ambiente apresenta resultados do Projeto de Olho no Lixo, na comunidade da Rocinha, Zona Sul do Rio, Instituto Estadual do Ambiente, News, 17 th of June 2016, Online at: http://www.inea.rj.gov.br/secretario-do-ambiente-apresentaresultados-do-projeto-de-olho-no-lixo-na-comunidade-da-rocinhazona-sul-do-rio/
IPP, 2017. Armazém de Dados, Institute Pereira Pasos, Prefeitura of Rio de Janeiro, Online at: http://www.data.rio/

IBGE, 2017. Instituto Brasileiro de Geografia e Estatística, Online at: https://www.ibge.gov.br/

Mattos L.C. and Farias M. J., 2011. Manual do Biodigestor Sertanejo, Projeto Manejo Sustentavel de Terras no Sertao, Ediçao do Projeto Dom Helder Camara, Recife.

PMGIRS, 2016. Plano Municipal de Gestão Integrada de Resíduos Sólidos 2017-2020, Prefeitura da Cidade do Rio de Janeiro.

QGIS Development Team, 2017. QGIS Geographic Information System. Open Source Geospatial Foundation. Online at: http://qgis.org

R Core Team, 2015. R: A language and environment for statistical computing. R Foundation for Statistical Computing, Vienna, Austria. Online at: https://www.R-project.org/.

Rekow, L., 2016. On Unstable Ground: Issues Involved in Greening Space in the Rocinha Favela of Rio De Janeiro, Journal of Human Security, 12.1, 52-73, 10.12924/johs2016.12010052

Schöpfel, J., Farace, D.J. (2010). “Grey Literature”, Encyclopedia of Library and Information Sciences 3rd edition, 2029-2039

Silva, J. M. P., 2015. Plano Socioespacial da Rocinha - Plano, projetos e obra: Conflitos e contradições, in Práticas recentes de intervenções contemporâneas em cidades da América Latina, edited by Maria de Lourdes Zuquim e Camila D'Ottaviano, University of São Paulo.

SNIS, 2017. Sistema Nacional de Informações sobre Saneamento, Online at: http://www.snis.gov.br/

Tadi M., Vahabzadeh Manesh S., 2014. Transformation of an urban complex system into a more sustainable form via integrated modification methodology (I.M.M). The International Journal of Sustainable Development and Planning, 9.4, WIT Press Southampton, UK, ISSN: 1743-7601

UFRJ, 2015. Diagnóstico Preliminar de Resíduos Sólidos da Cidade do Rio de Janeiro - Relatório Executivo, Universidade Federal do Rio de Janeiro, COPPE (Programa de Planejamento Energético/Centro Clima).

UN-Habitat, 2010. UNHabitat Solid Waste Management in the World's Cities, UN-Habitat

Wickham, H., 2009. ggplot2: Elegant Graphics for Data Analysis. Springer-Verlag New York.

Wickham, H., 2011. The Split-Apply-Combine Strategy for Data Analysis. Journal of Statistical Software (JSS), 40(1), 1-29. Online at: http://www.jstatsoft.org/v40/i01/.

Wickham, H., 2007. Reshaping data with the reshape package. JSS, 21(12).

Wilson D. C., Rodic L., Cowing M. J., Velis C.A., Whiteman A.D., Scheinberg A., Vilches R., Masterson D., Stretz J., Oelz B., (2015), "Wasteaware" Benchmark Indicators for Integrated Sustainable Waste Management in Cities, Waste Management, 35, 329-342. 